\title{
Correction to: New theories and applications of tempered fractional differential equations
}

\author{
Nazek A. Obeidat $(\mathbb{D} \cdot$ Daniel E. Bentil
}

Published online: 13 July 2021

(C) Springer Nature B.V. 2021

\section{Correction to: Nonlinear Dyn}

https://doi.org/10.1007/s11071-021-06628-4

Theorem (4.2) has been updated. The original article has been corrected.

Publisher's Note Springer Nature remains neutral with regard to jurisdictional claims in published maps and institutional affiliations.

The online version of the original article can be found under https://doi.org/10.1007/s11071-021-06628-4.

N. A. Obeidat $(\bowtie) \cdot$ D. E. Bentil

Department of Mathematics and Statistics, University of Vermont, Burlington VT 05405, USA

e-mail: nobeidat@uvm.edu

D. E. Bentil

e-mail: dbentil@uvm.edu 